\title{
The Flow-Through Cell as an In Vitro Dissolution Discriminative Tool for Evaluation of Gliclazide Solid Dispersions
}

\author{
Laila H. Emara ${ }^{1}$, Ebtesam W. Elsayed ${ }^{1}$, Ahmed A. El-Ashmawy ${ }^{1}$, Aya R. Abdou ${ }^{1}$, Nadia M. Morsi ${ }^{2}$ \\ ${ }^{1}$ Medical and Pharmaceutical Chemistry Department, Division of Pharmaceutical Industries, National Research Centre, 33 EL Bohou thst. (former EL \\ Tahrirst.), Dokki, Giza, Egypt. ${ }^{2}$ Department of Pharmaceutics, Faculty of Pharmacy, Cairo University, Cairo, 11562, Egypt.
}

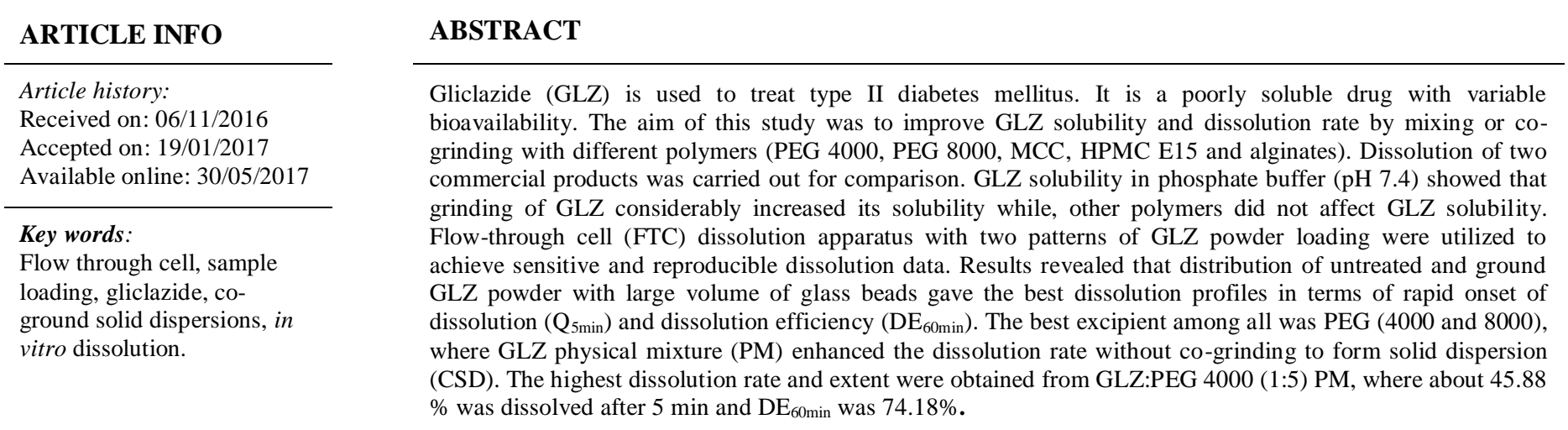

\section{INTRODUCTION}

Dissolution of drugs is one of the major evaluation criteria during drug product development whether we are dealing with a new molecule, a modified or a generic product. It is a prerequisite test required before carrying out bioavailability or bioequivalence studies (Wähling et al., 2011). Although the Flow through cell (FTC) became an official USP method since 1995 (USP App. 4) (Wähling et al., 2011), in vitro dissolution studies using this apparatus under different operational conditions and/or

\footnotetext{
* Corresponding Author

Dr. Laila Emara, Industrial Pharmacy Laboratory, Medical and Pharmaceutical Chemistry Department, Division of Pharmaceutical Industries, National Research Centre, 33 EL Bohouthst. (former EL Tahrirst.), Dokki, Giza, Egypt. E-mail: lhhemara @ yahoo.com
}

features are very few in literature (Emara et al., 2014a; Emara et al., 2014b; Emara et al., 2013; Emara et al., 2009; Krämer and Stippler, 2005; Beyssac and Lavigne, 2005; Fotaki and Reppas, 2005; Bhattachar et al., 2002; Emara et al., 2000). Our previous studies using the FTC proved that we should optimize the in vitro dissolution conditions for the finished product or during the preparation of different formulations to achieve accurate and reproducible results and to detect the effect of minor formulation changes upon storage. All these previous studies suggested that proper method of drug loading and the selection of cell design are crucial to obtain a reliable discriminating in vitro dissolution method otherwise, the dissolution results may become confusing or erroneous (Emara et al., 2014b; Emara et al., 2014a). In addition, the in vitro dissolution test using FTC could be modified to give a good in vitro-in vivo correlation (IVIVC) due to its flexibility in changing the dissolution conditions (Emara et al., 2000). 
Previously, we concluded that considerably different dissolution profiles of drug(s) from the same product and/or formulation were obtained upon utilizing variable features of the FTC (Emara et al., 2014a; Emara et al., 2014b; Emara et al., 2013; Emara et al., 2009; Emara et al., 2000). These variable features include, but are not limited to, type of flow (laminar, turbulent (Emara et al., 2014a; Emara et al., 2014b; Emara et al., 2009)), rate of flow (4 to $45 \mathrm{ml} / \mathrm{min}$ (Emara et al., 2009; Beyssacand Lavigne, 2005; Bhattachar et al., 2002)), small and large cell (Emara et al., 2014a; Emara et al., 2014b; Emara et al., 2009), open- or closed loop setup and $\mathrm{pH}$ of the dissolution medium (Emara et al., 2014b; Fotaki, 2011; Brown, 2005; Emara et al., 2000). Moreover, loading the test sample in different positions of the cell has also been studied (Emara et al., 2014a; Fotakiand Reppas, 2005; Brown, 2005).

Optimization of the FTC operational conditions should be carried out individually for each tested drug due to the differences in the specific physicochemical properties and/or dosage form of each drug (Emara et al., 2014a; Emara et al., 2014b; Emara et al., 2013; Emara et al., 2012; Emara et al., 2009; Emara et al., 2000). A practical example can be seen if the drug is degradable in a certain $\mathrm{pH}$ (e.g. Amoxicillin in acidic medium), the release rate study of the sustained-release preparations should be carried out in an open-loop setup of the FTC (Emara et al., 2013).

Enhancement of the dissolution rate of poorly soluble drugs, and hence its bioavailability, remains the major challenge during product development. Gliclazide (GLZ) is a poorly water soluble, second generation sulphonylurea oral hypoglycemic agent used in the treatment of type II diabetes mellitus. It has many added advantages such as protection of human beta-cells from apoptosis induced by intermittent high glucose, potentially slowing the progression of diabetic retinopathy, good general tolerability and low incidence of hypoglycemia (Del Guerra et al., 2007; Palmerand Brogden, 1993). However, GLZ exhibits low solubility and high permeability (Biopharmaceutical classification system, class: II) (Grbic et al., 2011). It also shows slow dissolution rate due to its hydrophobicity and poor wettability (Jondhale et al., 2012; Grbic et al., 2011; Biswal et al., 2008). Therefore, GLZ exhibits slow gastrointestinal absorption rate and high inter-subject variation for its bioavailability (Biswal et al., 2008; Jondhale et al., 2012; Biswal et al., 2009a; Palmerand Brogden, 1993).

Many approaches to enhance the dissolution rate of GLZ have been reported such as complexation with cyclodextrins, salt formation and preparation of different types of solid dispersions (El-Sabawiand Hamdan, 2014; Barzegar-Jalali et al., 2010; Biswal et al., 2008; Sapkal et al., 2007; Moyano et al., 1997b; Moyano et al., 1997a). Among all of these approaches, co-grinding is the simplest and the most environmentally desirable technique because it does not require toxic solvents or complex equipment (Barzegar-Jalali et al., 2010). Co-grinding of poorly soluble drugs with hydrophilic polymers lead to enhancement of their dissolution rate (Pandey et al., 2013; Swamy et al., 2010; Vogt et al., 2008; Yamada et al., 1999). This enhancement is thought to be due to particle size reduction and co-crystal formation (Jayasankar et al., 2006).

GLZ co-crystals were prepared by liquid-assisted grinding. An almost 2-fold improvement in the solubility and intrinsic dissolution was observed (Chadha et al., 2016). Solid dispersions obtained by co-milling of GLZ with amorphous silica or cross-linked swellable superdisintegrants like crosslinked polyvinylpyrrolidone, sodium starch glycolate and crosslinked carboxymethyl cellulose were quite effective in increasing the drug dissolution rate (Maggi et al., 2015). Barzegar-Jalali et al. (2010) reported that the type and ratio of carrier could play a major role in controlling the dissolution rate of GLZ from the co-ground samples. In addition, they found that co-grinding decreased the crystallinity and increased amorphousness of GLZ (Barzegar-Jalali et al., 2010). All these studies have evaluated the in vitro dissolution rates utilizing the conventional methods (USP apparatuses: I \& II).

This study aimed to prepare different physical mixtures (PMs) and co-ground solid dispersions (CSDs) of GLZ with different polymers (PEG 4000, PEG 8000, MCC and HPMC E15) to enhance its dissolution behavior. Some commercial GLZ tablet products were considered as references. Moreover, the evaluation of GLZ preparations was carried out utilizing special FTC operational features which were capable of proper discrimination between the different dissolution profiles of GLZ from the tested PMs and CSDs.

\section{MATERIALS AND METHODS}

\section{Materials}

Gliclazide (GLZ) powder (particle size $<15 \mu \mathrm{m}$ ) was kindly donated from Sigma Pharma, Cairo, Egypt. GLZ market products were: Diamicron ${ }^{\circledR} 80 \mathrm{mg}$ Tablets, Servier, Egypt (batch number: 19920) and Diamicron ${ }^{\circledR} 60 \mathrm{mg}$ MR Tablets, Servier, Egypt (batch number: 20378).

Reagent grade chemicals were used unless otherwise indicated. Avicel PH-101(MCC, microcrystalline cellulose, particle size $50 \mu \mathrm{m}$, Fluka, Germany), hydroxylpropyl methyl cellulose (HPMC E15, Sigma, USA), Polyethylene glycol 4000 (WNLAB, UK), Polyethylene glycol 8000 (Fluka, Germany), Alginic acid sodium salt-high viscosity (Alg-High, Sigma, USA), Alginic acid sodium salt-medium viscosity (Alg-Med, Sigma, USA), Alginic acid sodium salt-low viscosity (Alg-Low, Sigma, USA) were used in the preparation of different CSDs and PMs. Potassium dihydrogen orthophosphate (ADWIC, Egypt), sodium hydroxide (ADWIC, Egypt) and Milli-RO purified water (Millipore Corp., Billerica, MA, USA) were used to prepare the dissolution medium.

\section{Preparation of co-ground solid dispersions and physical mixtures}

PMs as well as CSDs of GLZ with excipients in different ratios were prepared (Tables $1-4$ ). For CSDs, a fixed weight of GLZ with the corresponding excipient were co-ground in a mortar 
for 5 min (Emara et al., 2016; Jayasankar et al., 2006). PMs of GLZ with different excipients were manually mixed in a lowdensity polyethylene bag (Emara et al., 2016; Nama et al., 2008) for $5 \mathrm{~min}$. Content uniformity tests were carried out and the results were found within the acceptable range.

\section{Solubility test}

Solubility measurements were performed according to Higuchi and Connors method (Higuchiand Connors, 1965). For each experiment, a specified weight, containing an excess amount of GLZ, was weighed into stoppered glass test tubes and $5 \mathrm{ml}$ of distilled water or phosphate buffer of $\mathrm{pH} 7.4$ was added (Tables 1 and 2). Samples were shaken at $37^{\circ} \mathrm{C}$ for $48 \mathrm{~h}$ (Grbic et al., 2011) in a temperature-controlled shaking water bath (Lab-Line, USA) at $250 \mathrm{rpm}$ and then filtered through $0.45 \mu \mathrm{m}$ filter (Mellix, USA). The filtrate was suitably diluted and analyzed spectrophotometrically at a predetermined $\lambda_{\max } 225 \mathrm{~nm}$ against water or phosphate buffer $\mathrm{pH} 7.4$ as blank. All solubility experiments were carried out in triplicates.

Table 1: GLZ measured solubility in water and phosphate buffer (pH 7.4) after $48 \mathrm{~h}$ at $37^{\circ} \mathrm{C}$.

\begin{tabular}{ccc}
\hline \multirow{2}{*}{ GLZ (powder) } & \multicolumn{2}{c}{ Solubility $(\mathbf{m g} / \mathbf{m l}) \pm$ S.D. } \\
\cline { 2 - 3 } & Water & pH 7.4 \\
\hline Untreated & $0.075 \pm 0.004$ & $1.56 \pm 0.06$ \\
Ground & - & $1.87 \pm 0.06$ \\
\hline
\end{tabular}

Table 2: GLZ measured solubility from different physical mixtures (PMs) and co-ground solid dispersions (CSDs) in phosphate buffer ( $\mathrm{pH} 7.4)$ after $48 \mathrm{~h}$ at $37^{\circ} \mathrm{C}$.

\begin{tabular}{ccc}
\hline & \multicolumn{2}{c}{ GLZ Solubility $(\mathbf{m g} / \mathbf{m l}) \pm$ S.D. } \\
\cline { 2 - 3 } Drug carrier system & PM & CSD \\
\hline GLZ:MCC (1:1) & $1.64 \pm 0.06$ & $1.75 \pm 0.03$ \\
GLZ:MCC (1:5) & $1.47 \pm 0.09$ & $1.32 \pm 0.02$ \\
GLZ:MCC (1:10) & $1.37 \pm 0.01$ & - \\
GLZ:Alg-Low (1:1) & - & $1.64 \pm 0.09$ \\
GLZ:Alg-Med (1:1) & - & $1.64 \pm 0.03$ \\
GLZ:Alg-High (1:1) & - & $1.60 \pm 0.01$ \\
GLZ:HPMC E15 (1:1) & - & $1.68 \pm 0.18$ \\
GLZ:PEG 8000 (1:5) & - & $1.44 \pm 0.04$ \\
\hline
\end{tabular}

\section{In vitro dissolution test}

In vitro dissolution tests were carried out using the closed loop setup of FTC [USP Apparatus 4, a Dissotest CE-6 equipped with a CY 7-50 piston pump (Sotax, Switzerland)]. A Built-in filtration system with $0.7-\mu \mathrm{m}$ Whatman glass micro-fiber $(\mathrm{GF} / \mathrm{F}$ and GF/D) and glass wool was used throughout the study. The dissolution medium was $900 \mathrm{ml}$ filtered and degassed phosphate buffer $(\mathrm{pH} 7.4)$ maintained at $37.0 \pm 0.5{ }^{\circ} \mathrm{C}$ and pumped at a flow rate of $8 \pm 0.2 \mathrm{ml} / \mathrm{min}$. Samples were collected at the predetermined time intervals and replaced with fresh dissolution medium. Collected samples were analyzed UV/ spectrophotometrically at $225 \mathrm{~nm}$ against phosphate buffer $\mathrm{pH} 7.4$ as blank.

\section{Tablet loading into the FTC}

For the evaluation of GLZ market products, tablets were loaded in the small FTC cell $(\varnothing 12 \mathrm{~mm})$, allowing for turbulent flow of the dissolution medium.

\section{Powder sample loading:}

Two FTC cell patterns (A and B), using the large cell ( $\varnothing$ $22.6 \mathrm{~mm}$ ), allowing for laminar flow of the dissolution medium, were employed (Figure 1). For each preparation, a weight of powder that was equivalent to $80 \mathrm{mg}$ GLZ was evaluated:

For cell pattern (A): homogeneously mixed powder (GLZ, PM or CSD) with glass beads (1:2, respectively) was loaded into the cell followed by addition of glass beads to fill the remaining space within the cell.

While for cell pattern (B): homogeneously mixed powder (GLZ, PM or CSD) with a quantity of glass beads sufficient to fill up to the score of tablet holder (Fotaki, 2011) was loaded into the cell followed by addition of a small amount of glass beads just to fill the remaining space within the cell.

\section{Similarity of the dissolution profiles:}

Dissolution profiles of some CSDs or PMs were compared by calculating the similarity factor $\left(f_{2}\right)$ as proposed by Moore and Flanner (Moore and Flanner, 1996), defined as follows:

$$
f_{2}=50 \log \left\{\left[1+\frac{1}{n} \Sigma w_{t}\left(R_{t}-T_{t}\right)^{2}\right]^{-0.5} \times 100\right\}
$$

Equation (1), (Moore and Flanner, 1996)

Where $R_{t}$ is the percentage of dissolved drug for a reference batch at time point $t, T_{t}$ is the percentage of dissolved drug for the test batch, $\mathrm{n}$ is the number of time points and $\mathrm{w}_{\mathrm{t}}$ an optional weight factor. The weight factor can be adjusted to give high or low weightings to selected time points as required. For example, if it is important to achieve a certain dissolution level by $40 \mathrm{~min}$, the 40 min time point should be given a high weighting. The present study uses $\mathrm{w}_{\mathrm{t}}=1$, meaning that each time point is weighted equally. For each experiment, the calculations were made on the mean of the triplicates.

Similarity factor value(s) can be between 0 and 100 . The value is 100 when the test and the reference profiles are identical and approaches zero as the dissimilarity increases, but because $f_{2}$ is a $\log$ function small differences in profile lead to a large drop in $f_{2}$ (Anderson et al., 1998). The FDA suggests that two dissolution profiles are considered similar if the similarity factor $f_{2}$ is between 50 and 100 (FDA, 1997). 

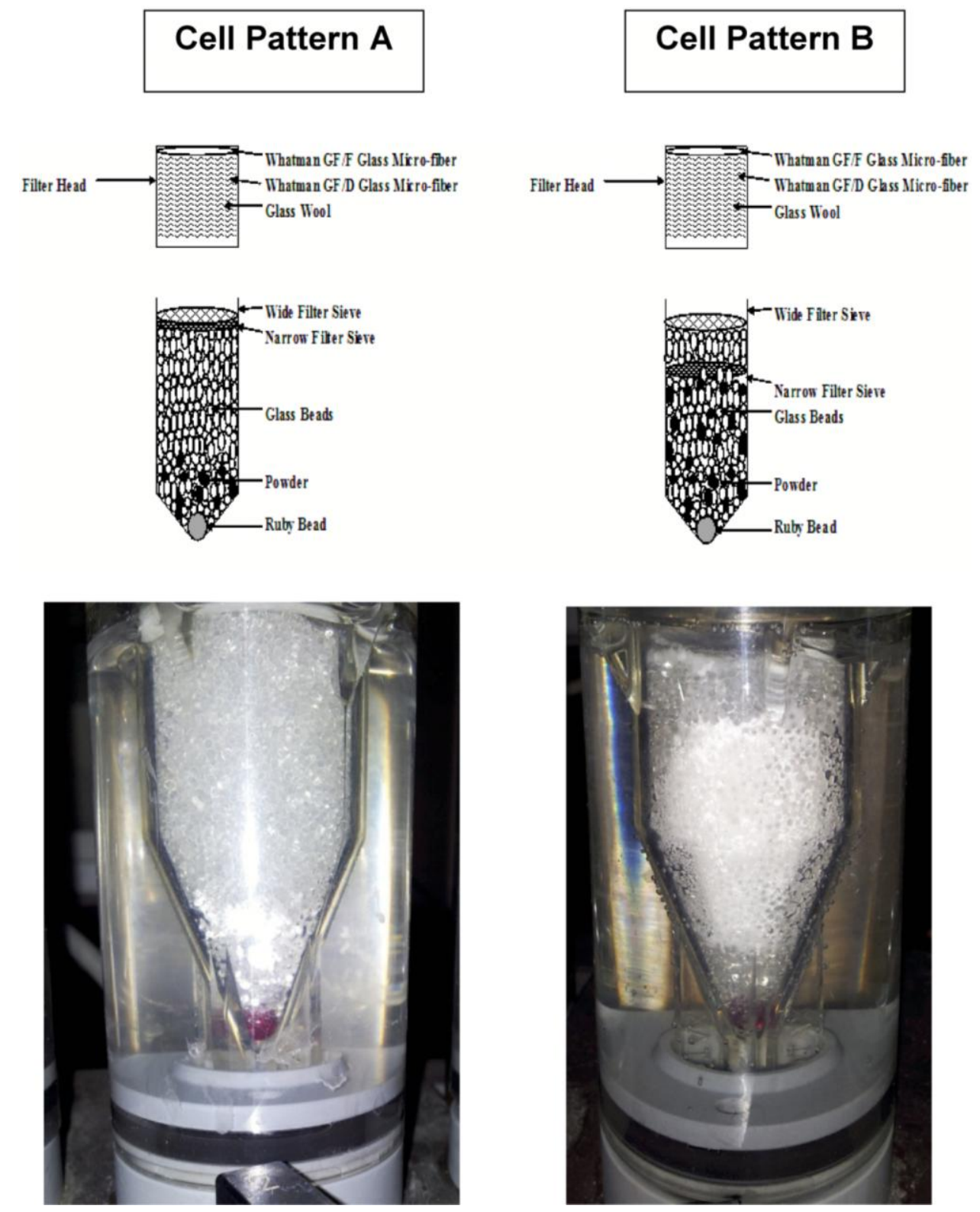

Fig. 1: Schematic diagrams and photographs showing the two FTC cell patterns (A and B) employed for sample loading.

\section{Dissolution efficiency}

Dissolution efficiency (DE) was calculated from the area under the dissolution curve at time $(t)$, measured using the trapezoidal rule, and expressed as percentage of the area of the rectangle described by $100 \%$ dissolution in the same time "Equation 2" (Khan, 1975).

$$
\mathrm{DE}=\frac{\int_{0}^{t} y \cdot d t}{y_{100} \cdot t} \cdot 100 \% \quad \text { Equation }(2),(\text { Khan }, 1975)
$$

\section{RESULTS AND DISCUSSION}

There were very few studies in literature that evaluated the solubility of GLZ in water and phosphate buffer ( $\mathrm{pH} 7.4$ ) (Maggi et al., 2015; Grbic et al., 2011; Biswal et al., 2009a).
Table 1 showed the solubility of untreated GLZ powder, after shaking for $48 \mathrm{~h}$ at $37^{\circ} \mathrm{C}$ in water and phosphate buffer at $\mathrm{pH}$ 7.4. In water, the solubility of GLZ was found to be $(0.075 \pm 0.004$ $\mathrm{mg} / \mathrm{ml}$ ). While, in a previous study of Biswal et al. (Biswal et al., 2009a), the solubility of GLZ in water after shaking for $72 \mathrm{~h}$ at $37^{\circ} \mathrm{C}$ was reported to be $0.8 \mathrm{mg} / \mathrm{ml}$ which was very far from our results. Also, in another study by Grbic et al. (Grbic et al., 2011), the solubility of GLZ was $0.5 \mathrm{mg} / \mathrm{ml}$ after shaking for $48 \mathrm{~h}$ at 37 ${ }^{\circ} \mathrm{C}$ in neutral medium. It is worthy to mention that, in our study, the particle size of GLZ was less than $15 \mu \mathrm{m}$, while both Biswal et al. (Biswal et al., 2009a) and Grbic et al. (Grbic et al., 2011) did not mention GLZ particle size. Maggi et al. (Maggi et al., 2015) have studied the concentrations of GLZ, with a mean volume diameter of $38.41 \pm 30.64 \mu \mathrm{m}$, (at $21^{\circ} \mathrm{C}$ for $24 \mathrm{~h}$ ) in distilled water at different time intervals. They found that the amount of GLZ 
dissolved after $4 \mathrm{~h}$ was $0.0539 \mathrm{mg} / \mathrm{ml}$ and almost remained constant till $24 \mathrm{~h}$ (about $0.0540 \mathrm{mg} / \mathrm{ml}$ ), confirming that GLZ reached a thermodynamic equilibrium in solution. Table 1 showed that the solubility of untreated and ground GLZ powder in phosphate buffer $\mathrm{pH} 7.4$ was increased from $1.564 \pm 0.064$ to $1.872 \pm 0.058 \mathrm{mg} / \mathrm{ml}$, respectively (Table 1 ), which might be due to particle size reduction and distribution (Loh et al., 2015; Khadka et al., 2014). While, the study of Grbic et al. (Grbic et al., 2011)

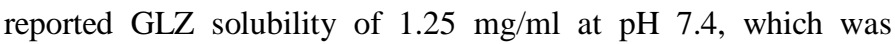
slightly lower than our results.

Table 2 showed that PM of GLZ:MCC (1:1) slightly increased GLZ solubility compared to that of untreated powder (1.64 \pm 0.06 and $1.56 \pm 0.06 \mathrm{mg} / \mathrm{ml}$, respectively). While, increasing MCC to drug ratio (1:5 and 1:10) showed a pronouncedly decreased GLZ solubility. In case of co-ground GLZ with different carriers, the measured solubility were decreased compared to ground GLZ powder as shown in Tables $(1 \& 2)$ where the highest solubility was obtained from ground GLZ without any additives.

The dissolution profiles, in phosphate buffer ( $\mathrm{pH} 7.4)$, of two GLZ commercial products available in Egyptian market were depicted in (Figure 2). It was found that, both Diamicron ${ }^{\circledR} 80 \mathrm{mg}$ and Diamicron ${ }^{\circledR} 60 \mathrm{mg}$ MR showed very slow dissolution rates that failed to meet the requirements described by the British Pharmacopoeia for conventional-release and prolonged-release oral dosage forms (British Pharmacopoeia, 2011). Moreover, Diamicron $^{\circledR} 80 \mathrm{mg}$ tablets showed a dissolution profile that is similar to the modified release product Diamicron ${ }^{\circledR} 60 \mathrm{mg}$ MR tablets $\left(f_{2}=76\right)$.

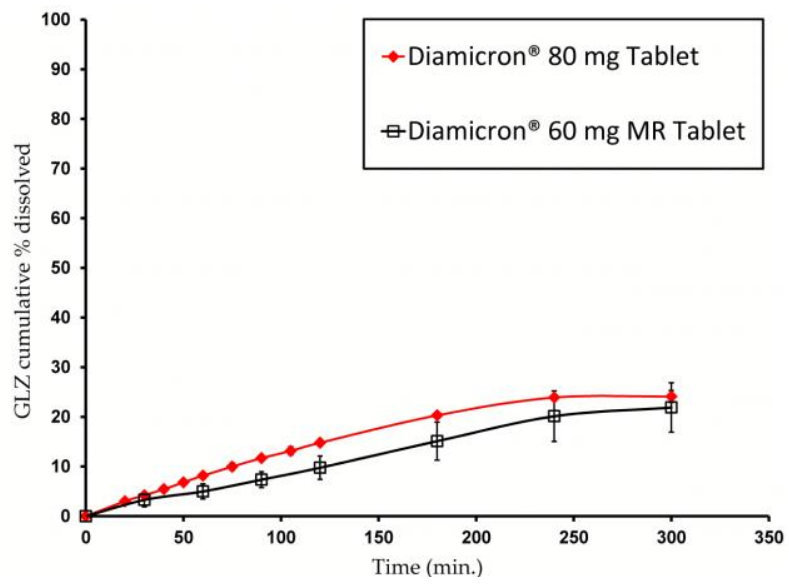

Fig. 2: Dissolution profiles of two GLZ products available in the Egyptian market (Diamicron ${ }^{\circledR} 80 \mathrm{mg}$ and Diamicron ${ }^{\circledR} 60 \mathrm{mg}$ MR, Servier, Egypt) in phosphate buffer (pH 7.4) employing the FTC apparatus.

Figure 3 and Table 3 showed the dissolution profiles of untreated and ground GLZ powder for two different cell loading patterns. Ground GLZ powder showed faster onset of dissolution (i.e. $\mathrm{Q}_{5 \mathrm{~min}}$ ) compared to untreated GLZ powder in both patterns A $\&$ B. Moreover, the two patterns proposed showed a considerable difference within the same test sample and this would be an important factor to consider in selecting the dissolution conditions to overcome the erratic data and poor detection of any minor formulation changes which might have its impact on product bioavailability. The calculated $f_{2}$ values were found to be 38 and 42 (Figure 3) for the untreated and ground drug, respectively, employing the two patterns (A \& B) within the same test samples, indicating dissimilarity between the dissolution profiles obtained. This could be attributed to the large volume of powder dispersion and distribution within glass beads in case of pattern-B (Figure1). Distribution of the tested drug powder within the glass beads could be critical for giving reproducible in vitro dissolution data, with a low standard deviation of the test replicates, as previously reported (Eaton et al., 2012; Stippler, 2011; Bhattachar et al., 2002)

Table 3: $\mathrm{Q}_{5 \min } *$ and dissolution efficiency values $\left(\mathrm{DE}_{60 \mathrm{~min}}\right)$ of untreated and ground GLZ powder employing different FTC cell patterns.

\begin{tabular}{|c|c|c|c|c|}
\hline \multirow{3}{*}{$\begin{array}{c}\text { GLZ } \\
\text { powder }\end{array}$} & \multicolumn{4}{|c|}{ FTC Pattern } \\
\hline & \multicolumn{2}{|c|}{$\mathbf{A}$} & \multicolumn{2}{|c|}{ B } \\
\hline & $Q_{5 \min }(\%)$ & $\begin{array}{c}\mathbf{D E}_{60 \text { min }} \\
(\%)\end{array}$ & $Q_{5 \min }(\%)$ & $\begin{array}{c}\mathbf{D E}_{60 \min } \\
(\%) \\
\end{array}$ \\
\hline Untreated & $12.79 \pm 0.49$ & 38.32 & $26.23 \pm 1.46$ & 55.02 \\
\hline Ground & $14.6 \pm 1.19$ & 42.77 & $36.50 \pm 2.50$ & 57.74 \\
\hline
\end{tabular}

$* \mathrm{Q}_{5 \min }=\%$ drug dissolved after 5 min.
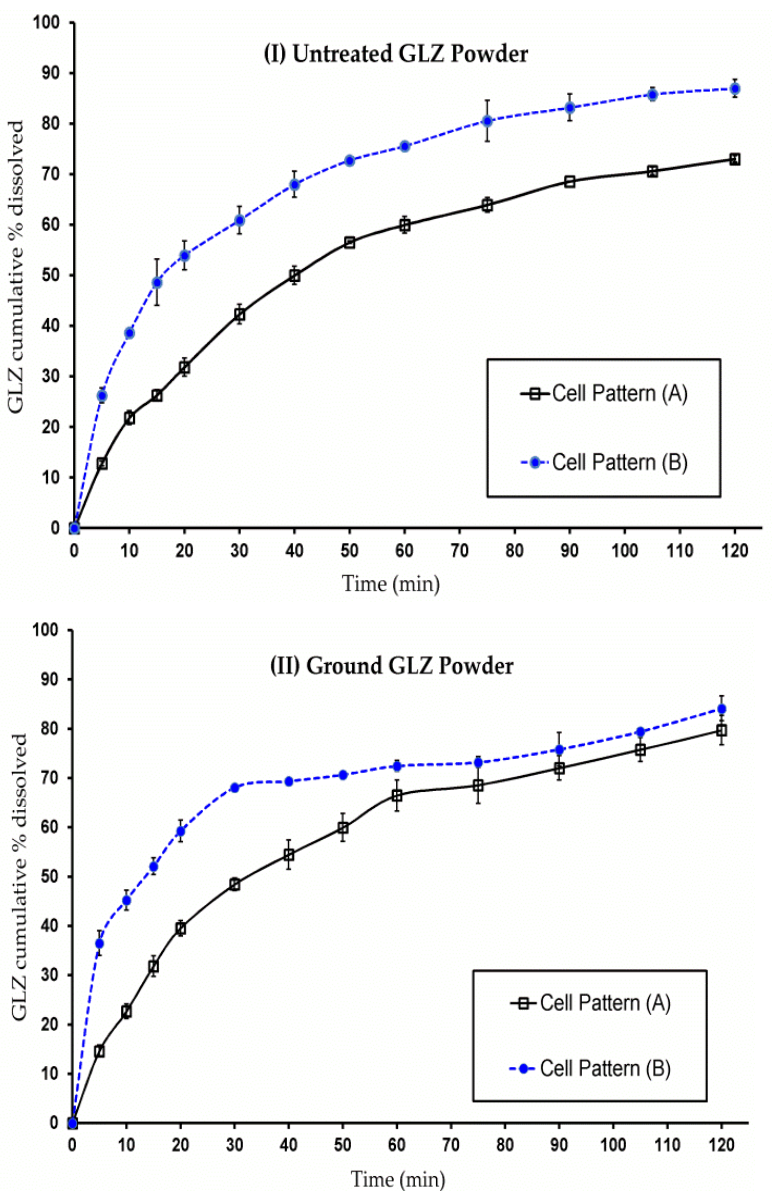

Fig. 3: Dissolution profiles of GLZ powder employing two different FTC cell patterns (A \& B) in phosphate buffer ( $\mathrm{pH}$ 7.4).

Therefore, pattern-B might solve the problems of aggregation, agglomeration and poor wettability of GLZ powder, which were suspected to be the reason of slowing down the 
dissolution rate of the untreated drug powder using pattern-A. Consequently, pattern-B was selected for the in vitro dissolution testing of different GLZ PMs and CSDs. This provided a practical example of one of the advantages of FTC over the conventional USP I \& II dissolution testers that it enabled optimization of the operational conditions and features of the dissolution test for each individual drug.

PM and CSD of GLZ with different polymers (MCC, HPMC E15, PEG 4000, PEG 8000) were prepared and their corresponding $\mathrm{Q}_{5 \min }$ and $\mathrm{DE}_{60 \min }$ values were listed in Table 4.

Table 4: Composition of different physical mixtures (PMs) and co-ground solid dispersions (CSDs) with their corresponding $\mathrm{Q}_{5 \min }$ and dissolution efficiency values $\left(\mathrm{DE}_{60 \mathrm{~min}}\right)$.

\begin{tabular}{lllll}
\hline Drug carrier system & PM & \multicolumn{3}{l}{ CSD } \\
\cline { 2 - 5 } & $\mathbf{Q}_{5 \min }(\boldsymbol{\%})$ & $\begin{array}{l}\mathbf{D E}_{\mathbf{6 0}} \\
{ }_{\min }(\boldsymbol{\%})\end{array}$ & $\mathbf{Q}_{\text {(5in }}(\boldsymbol{\%})$ & $\begin{array}{l}\mathbf{D E}_{\mathbf{6 0} \min } \\
(\boldsymbol{\%})\end{array}$ \\
\hline GLZ:MCC (1:5) & $32.29 \pm 2.40$ & 59.63 & $23.76 \pm 1.69$ & 41.10 \\
GLZ:HPMC E15 (1:1) & - & - & $27.20 \pm 0.05$ & 41.74 \\
GLZ:HPMC E15(1:5) & - & - & $7.87 \pm 2.64$ & 15.79 \\
GLZ:HPMCE15 (1:10) & - & - & $4.06 \pm 1.30$ & 8.00 \\
GLZ:PEG 8000 (1:5) & $29.43 \pm 2.38$ & 66.69 & $35.92 \pm 1.49$ & 67.73 \\
GLZ:PEG 4000 (1:5) & $45.88 \pm 2.77$ & 74.18 & - & - \\
\hline
\end{tabular}

Figure (4) showed the dissolution profile of GLZ:MCC (1:5). It was found that the PM gave higher dissolution rate than the CSD. The PM (GLZ:MCC, 1:5) gave a dissolution rate similar to the ground GLZ powder $\left(f_{2}=71\right)$, where the early initial amount of GLZ dissolved $\left(\mathrm{Q}_{5 \mathrm{~min}}\right)$ as well as $\left(\mathrm{DE}_{60 \mathrm{~min}}\right)$ values were 36.50 \& $32.29 \%$ and $57.74 \& 59.63 \%$, for ground GLZ and PM GLZ:MCC (1:5), respectively (Table 4). MCC might have acted as a diluent that suppresses the aggregation and agglomeration of GLZ powder, and hence increased GLZ surface to volume ratio exposed to the dissolution media. Also, this enhancement of the dissolution rate upon mixing with MCC is thought to be due to the hydrophilic nature of MCC particles that improved the wettability of the hydrophobic drug particles (Valizadeh et al., 2007; Barzegar-Jalali et al., 2006; Friedrich et al., 2005). On the other hand, Figure (4) and Table (4) showed that CSD (GLZ:MCC, 1:5) considerably suppressed the dissolution rate of GLZ compared to the ground GLZ $\left(f_{2}=39\right)$ and PM (GLZ:MCC, 1:5) $\left(f_{2}=35\right)$. MCC is considered as a plastic material and a water insoluble diluent (Katdare and Chaubal, 2006), which might be the reason for decreasing the dissolution rate of GLZ from CSD. This might enforce the drug particles to be intimately incorporated in MCC upon co-grinding and form a continuous plastic-like structure with the disappearance of the characteristic fiber-like structure of MCC as previously described (Emara et al., 2016).

Therefore, the dissolution of GLZ was not increased. We should address here the major influence of the exerted force during co-grinding on the fiber network structure of MCC, which was not observed with PM. This means that MCC could not be a promising excipient for preparing a CSD of GLZ, where the inherent physical properties of MCC could be dramatically altered by grinding techniques. Co-grinding of GLZ with MCC might possibly collapse the fiber network structure of MCC with reduction of pore size. Eventually, formation of tight networks around the solid drug particles occurred. This led to reduction of water uptake ability which lowered gliclazide release from GLZ:MCC CSD (Kolakovic, 2013). This result was found to be in a good agreement with a previous study of Emara et al. (Emara et al., 2016), where, MCC meloxicam CSD drastically decreased the amount of meloxicam dissolved compared to those without MCC which might have acted as a dissolution retarding polymer after grinding.

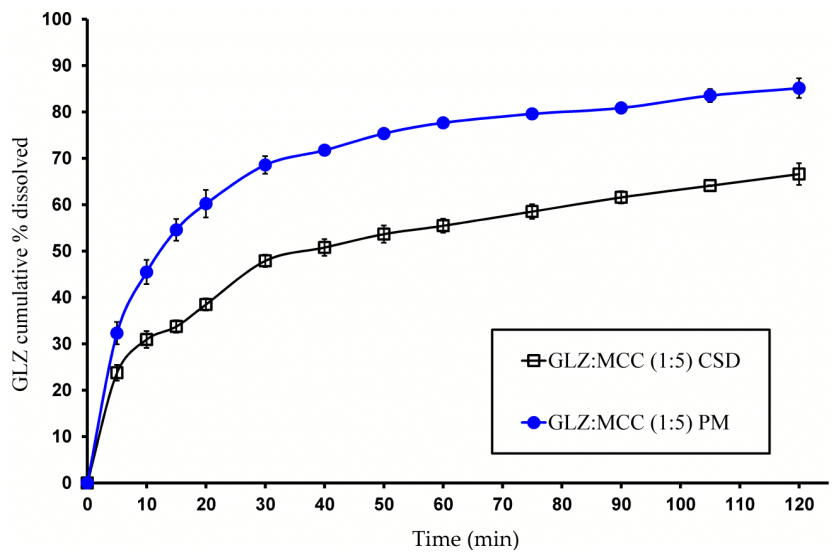

Fig. 4: Dissolution profiles of GLZ from its PM and CSD with MCC (1:5, drug to polymer ratio) in phosphate buffer $\mathrm{pH} 7.4$ (FTC cell pattern B).

The dissolution rate of GLZ from the CSDs with HPMC E15 showed that increasing HPMC E15 in GLZ: polymer ratio (1:1, 1:5 and 1:10) slowed down the dissolution rate (Figure 5). Moreover, co-grinding with any ratio of HPMC E15 gave a slower dissolution rate than the untreated drug (Table 4). In contact with water, HPMC swells to form a gel, which acts as a barrier to drug diffusion. In addition, it is reported that increasing HPMC concentration or using higher viscosity grades increases the strength of the gel layer and retards the penetration of water thus delaying drug dissolution (Ghimire et al., 2010). In addition, this might be attributed to the swelling behavior of HPMC E15 that leads to increasing viscosity of the dissolution medium and hence retarding drug dissolution (Colombo et al., 2000).

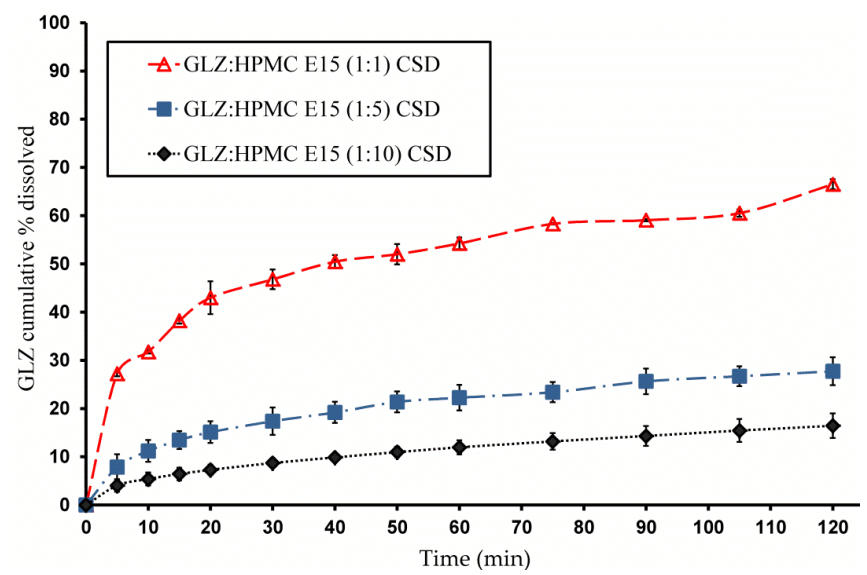

Fig. 5: Effect of HPMC E15 ratio on the dissolution profile of GLZ from different CSDs with HPMC E15 in phosphate buffer pH 7.4 (FTC cell pattern B). 
Physical mixing or co-grinding of GLZ with PEG 8000 (1:5) enhanced the dissolution rate (Figure 6, Table 4), where both $\mathrm{Q}_{5 \min }$ and the $\mathrm{DE}_{60 \mathrm{~min}}$ were almost the same for PM and CSD.. In addition, the PM and CSD with PEG 8000 showed similar dissolution rates of $\operatorname{GLZ}\left(f_{2}=73\right)$. This enhancement of the dissolution rate might be due to the known solubilizing capability of PEG 8000 (Koh et al., 2013; Biswal et al., 2009b). PEG 8000 is known to reduce particle aggregation, increase wettability and dispersibility and alter the surface properties of drug particles (Koh et al., 2013; Biswal et al., 2009b). Figure (6) and Table (4) showed that the dissolution profile of GLZ from the PM of GLZ:PEG 4000 (1:5) showed the fastest onset of dissolution $\left(\mathrm{Q}_{5 \mathrm{~min}}\right.$ $=45.88 \%)$ and dissolution rate $\left(\mathrm{DE}_{60 \mathrm{~min}}=74.18 \%\right)$ among all of the tested preparations. Different types of PEG have the ability to enhance dissolution by increasing the wettability and solubility of different drugs (Koh et al., 2013).

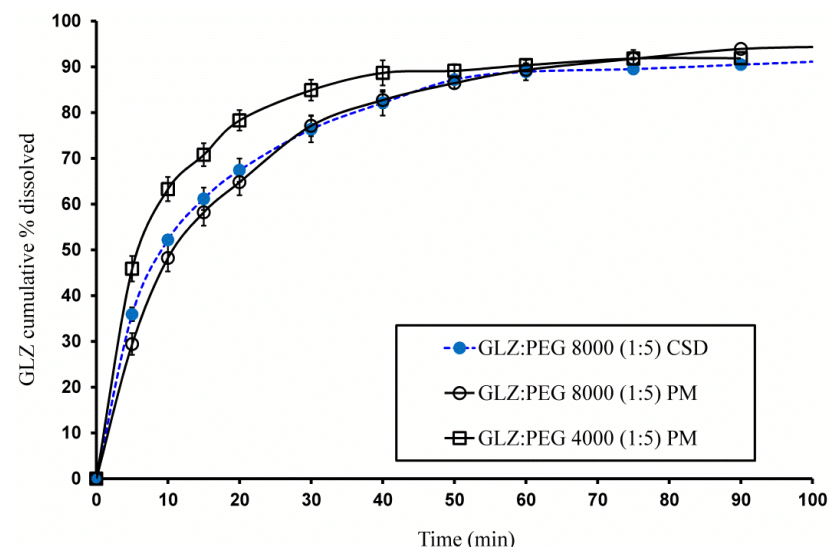

Fig. 6: Dissolution profiles of GLZ from PMs and CSD with PEG 4000 and PEG 8000 (1:5, drug to polymer ratio) in phosphate buffer pH 7.4 (FTC cell pattern B).

\section{CONCLUSION}

Testing of drug powder preparations requires proper selection of FTC operational conditions to obtain trustful and reproducible in vitro dissolution results with high accuracy. Improper selection of different features of FTC will give misleading dissolution data. The most promising preparation was the physical mixture with PEG 4000 (GLZ:PEG4000, 1:5). Meanwhile, all the proposed test preparations showed much faster dissolution rates compared to the commercial products: Diamicron $^{\circledR} 80 \mathrm{mg}$ and Diamicron ${ }^{\circledR} 60 \mathrm{mg}$ MR tablets. Thanks for the presence of the FTC which could be able to optimize the dissolution conditions to solve all the problems of poor wettability, aggregation and agglomeration of hydrophobic drug particles.

Financial support and sponsorship: NIL.

Conflict of Interests: There are no conflicts of interest.

\section{REFERENCES}

Anderson N, Bauer M, Boussac N, Khan-Malek R, Munden P, Sardaro M. An evaluation of fit factors and dissolution efficiency for the comparison of in vitro dissolution profiles. J Pharm Biomed Anal, 1998; 17(4):811-822.

Barzegar-Jalali M, Nayebi AM, Valizadeh H, Hanaee J, Barzegar-Jalali A, Adibkia K, Anoush M, Sistanizad M. Evaluation of in vitro-in vivo correlation and anticonvulsive effect of carbamazepine after cogrinding with microcrystalline cellulose. J Pharm Pharm Sci, 2006; 9(3):307-316.

Barzegar-Jalali M, Valizadeh H, Shadbad M-RS, Adibkia K, Mohammadi G, Farahani A, Arash Z, Nokhodchi A. Cogrinding as an approach to enhance dissolution rate of a poorly water-soluble drug (gliclazide). Powder Technol, 2010; 197(3):150-158.

Beyssac E, Lavigne J. Dissolution study of active pharmaceutical ingredients using the flow through apparatus USP 4. Dissolution Technol, 2005; 12(2):23-25.

Bhattachar SN, Wesley JA, Fioritto A, Martin PJ, Babu SR. Dissolution testing of a poorly soluble compound using the flow-through cell dissolution apparatus. Int J Pharm, 2002; 236(1):135-143.

Biswal S, Sahoo J, Murthy P, Giradkar R, Avari J. Enhancement of dissolution rate of gliclazide using solid dispersions with polyethylene glycol 6000. AAPS PharmSciTech, 2008; 9(2):563-570.

Biswal S, Pasa GS, Sahoo J, Murthy PN. An Approach for improvement of the dissolution rate of gliclazide. Dissolution Technol, 2009a; 16(4):15-18.

Biswal S, Sahoo J, Murthy P. Characterisation of gliclazidePEG 8000 solid dispersions. Trop J Pharm Res, 2009b; 8(5):417-424. IV. London

British Pharmacopoeia. 2011. Appendix XII B; Dissolution. Vol

Brown W. Apparatus 4 flow through cell: Some thoughts on operational characteristics. Dissolution Technol, 2005; 30:5-28.

Chadha R, Rani D, Goyal P. Novel cocrystals of gliclazide: characterization and evaluation. Cryst Eng Comm, 2016; 18(13):22752283.

Colombo P, Bettini R, Santi P, Peppas NA. Swellable matrices for controlled drug delivery: gel-layer behaviour, mechanisms and optimal performance. Pharm Sci Technolo Today, 2000; 3(6):198-204.

Del Guerra S, Grupillo M, Masini M, Lupi R, Bugliani M, Torri S, Boggi U, Del Chiaro M, Vistoli F, Mosca F. Gliclazide protects human islet beta-cells from apoptosis induced by intermittent high glucose. Diabetes Metab Res Rev, 2007; 23(3):234-238.

Eaton JW, Tran D, Hauck WW, Stippler ES. Development of a performance verification test for USP apparatus 4. Pharmaceut Res, 2012; 29(2):345-351.

El-Sabawi D, Hamdan II. Improvement of dissolution rate of gliclazide through sodium salt formation. Dissolution Technol, 2014; 21(4):49-55.

Emara L, El-Menshawi B, Estefan M. In vitro-in vivo correlation and comparative bioavailablity of vincamine in prolongedrelease preparations. Drug Dev Ind Pharm, 2000; 26(3):243-251.

Emara LH, Taha NF, Mursi NM. Investigation of the effect of different flow-through cell designs on the release of diclofenac sodium SR tablets. Dissolution Technol, 2009; 16(2):23-31.

Emara LH, Abdou A, El-Ashmawy AA, Badr RM, Mursi NM. In vitro evaluation of floating matrix tablets of amoxicillin and metronidazole for the eradication of Helicobacter pylori. Int $\mathrm{J}$ Pharm Pharm Sci, 2012; 4(3):671-681.

Emara LH, Abdou AR, El-Ashmawy AA, Badr RM, Taha NF, Mursi NM. In vitro release evaluation of gastroretentive amoxicillin floating tablets employing a specific design of the flow-through cell. Dissolution Technol, 2013; 20(1):27-34.

Emara LH, Abdelfattah FM, Taha NF, El-ashmawy AA, Mursi NM. In vitro evaluation of ibuprofen hot-melt extruded pellets employing different designs of the flow through cell. Int J Pharm Pharm Sci, 2014a; 6(9):192-197.

Emara LH, Emam MF, Taha NF, El-ashmawy AA, Mursi NM. In-vitro dissolution study of meloxicam immediate release products using flow through cell (USP apparatus 4) under different operational conditions. Int J Pharm Pharm Sci, 2014b; 6(11):254-260.

Emara LH, El-Ashmawy AA, Tahaa NF, El-Shaffeib KA, Mahdeyb E-SM, Elkhollyc HK. Nano-crystalline cellulose as a novel 
tablet excipient for improving solubility and dissolution of meloxicam. $\mathbf{J}$ App Pharm Sci, 2016; 6(02):032-043.

FDA U. Guidance for Industry: Dissolution testing of immediate-release solid oral dosage forms. Food and Drug Administration, Center for Drug Evaluation and Research (CDER), 1997.

Fotaki N, Reppas C. The flow through cell methodology in the evaluation of intralumenal drug release characteristics. Dissolution Technol, 2005; 12(2):17-21.

Fotaki N. Flow-Through cell apparatus (USP apparatus 4): operation and features. Dissolution Technol, 2011; 18(4):46-49.

Friedrich H, Nada A, Bodmeier R. Solid state and dissolution rate characterization of co-ground mixtures of nifedipine and hydrophilic carriers. Drug Dev Ind Pharm, 2005; 31(8):719-728.

Ghimire M, Hodges LA, Band J, O'Mahony B, McInnes FJ, Mullen $\mathrm{AB}$, Stevens HN. In-vitro and in-vivo erosion profiles of hydroxypropylmethylcellulose (HPMC) matrix tablets. J Control Release, 2010; 147(1):70-75.

Grbic S, Parojcic J, Ibric S, Djuric Z. In vitro-in vivo correlation for gliclazide immediate-release tablets based on mechanistic absorption simulation. AAPS PharmSciTech, 2011; 12(1):165-171.

Higuchi T, Connors A. Phase-solubility techniques. 1965; 4:117-212.

Jayasankar A, Somwangthanaroj A, Shao ZJ, RodríguezHornedo N. Cocrystal formation during cogrinding and storage is mediated by amorphous phase. Pharmaceut Res, 2006; 23(10):2381-2392.

Jondhale S, Bhise S, Pore Y. Physicochemical investigations and stability studies of amorphous gliclazide. AAPS PharmSciTech, 2012; 13(2):448-459.

Katdare A, Chaubal M. 2006. Excipient development for pharmaceutical, biotechnology, and drug delivery systems: CRC Press.

Khadka P, Ro J, Kim H, Kim I, Kim JT, Kim H, Cho JM, Yun G, Lee J. Pharmaceutical particle technologies: An approach to improve drug solubility, dissolution and bioavailability. Asian J Pharm Sci, 2014; 9(6):304-316.

Khan K. The concept of dissolution efficiency. J Pharm Pharmacol, 1975; 27(1):48-49.

Koh P, Chuah J, Talekar M, Gorajana A, Garg S. Formulation development and dissolution rate enhancement of efavirenz by solid dispersion systems. Indian J Pharm Sci, 2013; 75(3):291.

Kolakovic R. Nanofibrillar cellulose in drug delivery. Helsinki: Faculty of Pharmacy, University of Helsinki; 2013.

Krämer J, Stippler E. Experiences with USP apparatus 4 calibration. Dissolution Technol, 2005; 12(2):33-39.

Loh ZH, Samanta AK, Sia Heng PW. Overview of milling techniques for improving the solubility of poorly water-soluble drugs. Asian J Pharm Sci, 2015; 10(4):255-274.

Maggi L, Canobbio A, Bruni G, Musitelli G, Conte U. Improvement of the dissolution behavior of gliclazide, a slightly soluble drug, using solid dispersions. J Drug Deliv Sci Technol, 2015; 26:17-23.

Moore JW, Flanner HH. Mathematical comparison of dissolution profiles. Pharm Tech, 1996; 20(6):64-74.

Moyano JR, Arias-Blanco MaJ, Ginés JM, Giordano F. Study of the complexation behaviour of gliclazide with partially methylated $\beta$ cyclodextrin in solution and solid state. Int J Pharm, 1997a; 157(2):239243.
Moyano JR, Arias-Blanco MJ, Ginés JM, Giordano F. Solidstate characterization and dissolution characteristics of gliclazide- $\beta$ cyclodextrin inclusion complexes. Int J Pharm, 1997b; 148(2):211-217.

Nama M, Gonugunta CSR, Veerareddy PR. Formulation and evaluation of gastroretentive dosage forms of clarithromycin. AAPS PharmSciTech, 2008; 9(1):231-237.

Palmer KJ, Brogden RN. Gliclazide. An update of its pharmacological properties and therapeutic efficacy in non-insulindependent diabetes mellitus. Drugs, 1993; 46(1):92-125.

Pandey A, Rath B, Dwivedi AK. Dissolution rate and bioavailability enhancement of co-ground mixtures of paliperidone, with different hydrophilic carriers. Int Curr Pharmaceut J, 2013; 2(3):70-77.

Sapkal N, Kilor V, Bhursari K, Daud A. Evaluation of some methods for preparing gliclazide- $\beta$-cyclodextrin inclusion complexes. Trop J Pharm Res, 2007; 6(4):833-840.

Stippler ES. Review of research paper: development of a performance verification test for USP apparatus 4. Dissolution Technol, 2011; 18(4):44-44.

Swamy P, Shilpa H, Shirsand S, Gada S, Kinagi M. Role of cogrinding in enhancing the in vitro dissolution characteristics of carvedilol. Int. J. Pharma Sci. Res, 2010; 1(5):232-237.

Valizadeh H, Zakeri-Milani P, Barzegar-Jalali M, Mohammadi G, Danesh-Bahreini M-A, Adibkia K, Nokhodchi A. Preparation and characterization of solid dispersions of piroxicam with hydrophilic carriers. Drug Dev Ind Pharm, 2007; 33(1):45-56.

Vogt M, Kunath K, Dressman JB. Dissolution enhancement of fenofibrate by micronization, cogrinding and spray-drying: comparison with commercial preparations. Eur J Pharm Biopharm, 2008; 68(2):283288.

Wähling C, Schröter C, Hanefeld A. Flow-through cell method and IVIVR for poorly soluble drugs. Dissolution Technol, 2011; 18(4):15 24.

Yamada T, Saito N, Imai T, Otagiri M. Effect of grinding with hydroxypropyl cellulose on the dissolution and particle size of a poorly water-soluble drug. Chem Pharm Bull (Tokyo), 1999; 47(9):1311-1313.

How to cite this article:

Emara LH, Elsayed EW, El-Ashmawy AA, Abdou AR, Morsi NM. The Flow-Through Cell as an in Vitro Dissolution Discriminative Tool for Evaluation of Gliclazide Solid Dispersions. J App Pharm Sci, 2017; 7 (05): 070-077. 